\title{
RELAÇÃO HIDRÁULICA ENTRE O COMPLEXO BELO HORIZONTE E O GRUPO BAMBUÍ NA PORÇÃO SUL DA APA CARSTE DE LAGOA SANTA, MG
}

\author{
Isabella B. Andrade ${ }^{1}$, Jéssica A. Barbosa ${ }^{1}$, Carolina G. Ribeiro ${ }^{1}$, Rodrigo S. Paula $^{1}$,Leila N. M. Velasquez ${ }^{1}$
} Instituto de Geociências, Universidade Federal de Minas Gerais, Av. Presidente Antônio Carlos 6627, 31270-901, Belo Horizonte, Minas Gerais, Brasil.
isa.andrade25@gmail.com(* autor correspondente).

Recebido em 1 de setembro de 2019, aceito em 15 janeiro de 2020

Resumo: A área desse estudo situa-se ao norte da cidade de Belo Horizonte, Minas Gerais, possui 432 km² $^{2}$ intersecciona parcialmente a porção sul da Área de Proteção Ambiental Federal (APA) Carste de Lagoa Santa. A porção basal é geologicamente caracterizada por granodioritos, granitos e gnaisses que definem as rochas do Complexo Belo Horizonte. Sobreposto a essa unidade por contato tectônico, estão as coberturas neoproterozoicas do Grupo Bambuí, que dá base para o topo constituam-se, pela Fm. Sete Lagoas, composta por metacalcários, e Fm. Serra de Santa Helena, constituída por metapelitos foliados. Lineamentos fotointerpretados associados com estruturas mensuradas em campo e dados hidráulicos de poços tubulares foram utilizados para a determinação do fluxo subterrâneo entre as rochas do Complexo Belo Horizonte e a Formação Sete Lagoas. A partir dos dados de capacidade específica obteve-se que a direção NE é tita como preferencial para transferência de fluxo d'água das fraturas do embasamento cristalino para as rochas supracrustais do Grupo Bambuí, de onde o fluxo segue preferencialmente na direção EW. Entretanto, os dados hidráulicos de produtividade levantados mostram que as faixas produtivas nas rochas carbonáticas se orientam preferencialmente nas direções N60-90E e N60-90W.

Palavras-Chave: Apa carste de lagoa santa; hidrogeologia; produtividade poços tubulares

Abstract: The hydraulic relation between Belo Horizonte complex and bambui group in the south portion of APA Carste de Lagoa Santa, mg. The area of this study is located north to the city of Belo Horizonte, Minas Gerais, has $432 \mathrm{~km}^{2}$ and embrace the southern portion of the Federal Environmental Protection Area (APA) Carste de Lagoa Santa. The geology is characterized by the Belo Horizonte Complex in the basal portion, composed of granodiorites, granites and gneisses. Superimposed on this unit by tectonic contact, there are neoproterozoic rocks of the Bambuí Group, which from the bottom to the top are constituted by the Sete Lagoas Fm., composed of limestone, and the Serra de Santa Helena Fm., consisting of phyllites. Photointerpreted lineaments associated with structures measured in the field and hydraulic data from tubular wells were used to determine the underground flow between rocks from the Belo Horizonte Complex and from the Sete Lagoas Fm. From the specific capacity data, it was obtained that the NE direction is preferential for transferring water flow from the fractures of the crystalline rocks to the supracrustal rocks of the Bambuí Group, from where the flow preferably goes in the EW direction. However, the hydraulic productivity data collected show the productive ranges in the carbonate rocks are oriented preferentially in the N60-90E and N60-90W directions.

Keywords: Apa carste de lagoa santa, hidrogeology, wells productivity

\section{NTRODUCÃO}

A área de estudo possui $432 \mathrm{~km}^{2}$ e insere-se parcialmente na Área de Proteção Ambiental (APA) Carste de Lagoa Santa, Minas Gerais, $30 \mathrm{~km}$ ao norte de Belo Horizonte (Figura 1). $O$ estudo possui cunho hidrogeológico e visa o entendimento acerca do comportamento hidráulico do fluxo d'água subterrâneo entre as rochas do Complexo Belo Horizonte e as rochas supracrustais da porção basal do Grupo Bambuí, na porção sul da APA Carste de Lagoa Santa.

Devido a grande fragilidade dos sistemas cársticos locais, com a sua riqueza paleontológica, arqueológica, fauna e flora, recursos minerais e água, é fundamental a realização de pesquisas visando a preservação da região e um melhor aproveitamento econômico, social, cultural e turístico. Ademais, apesar de realizados diversos estudos envolvendo a hidrogeologia cárstica na área (Projeto Vida (CPRM, 2003), APA Carste de Lagoa Santa (Viana et al., 2008) e Auler (1994)), nenhum deles abordou, com detalhes, as condições hidrogeológicas na região de contato da bacia metassedimentar com o embasamento.

Assim, esse estudo teve como objetivo investigar a existência de condições hidrogeológicas propícias à existência de fluxos de água subterrânea entre as zonas aquíferas do Complexo Granítico-Gnáissico-Migmatítico e as do Grupo Bambuí, a partir da relação estrutural e com uso de dados hidraúlicos de poços tubulares. 0 projeto conta com o apoio do Centro Nacional de
Pesquisa e Conservação de Cavernas (CECAV) e Instituto Chico Mendes de Conservação da Biodiversidade (ICMBio) e é executado pelo Instituto de Geociências na Universidade Federal de Minas Gerais (UFMG).

\section{SÍNTESE DA GEOLOGIA}

A área de estudo aloca-se na porção sul do Cráton São Francisco onde afloram as rochas do complexo graníticognáissico arqueano encobertos pelos sedimentos marinhos plataformais da porção basal da bacia do São Francisco. O embasamento é representado pelo Complexo Belo Horizonte, enquanto os sedimentos marinhos são representados pelas formações basais do Grupo Bambuí, Formação Sete Lagoas e Formação Serra de Santa Helena (RIBEIRO et al., 2003) (Figura 2).

Ribeiro et al., (2003) caracterizou a composição das rochas do Complexo Belo Horizonte como granitognáissicas e migmatíticas, variando de rochas bandadas foliadas a incipientes e isotrópicas. De maneira geral, são rochas leucocráticas a mesocráticas, de granulação fina a grossa.

Depositado discordantemente ao Complexo Granítico há a Formação Sete Lagoas, sobreposta pela Formação Serra de Santa Helena, pertencentes ao Grupo Bambuí. A primeira caracteriza-se por uma sucessão de rochas químicas carbonáticas de idade Neoproterozoica com espessura variando de 200 - 500 m. Já a segunda caracteriza-se por siltitos, argilitos, folhelhos, margas e calcarenitos que caracterizam a Formação Serra de Santa Helena (COSTA \& BRANCO, 1961, MARTINEZ, 2007). 

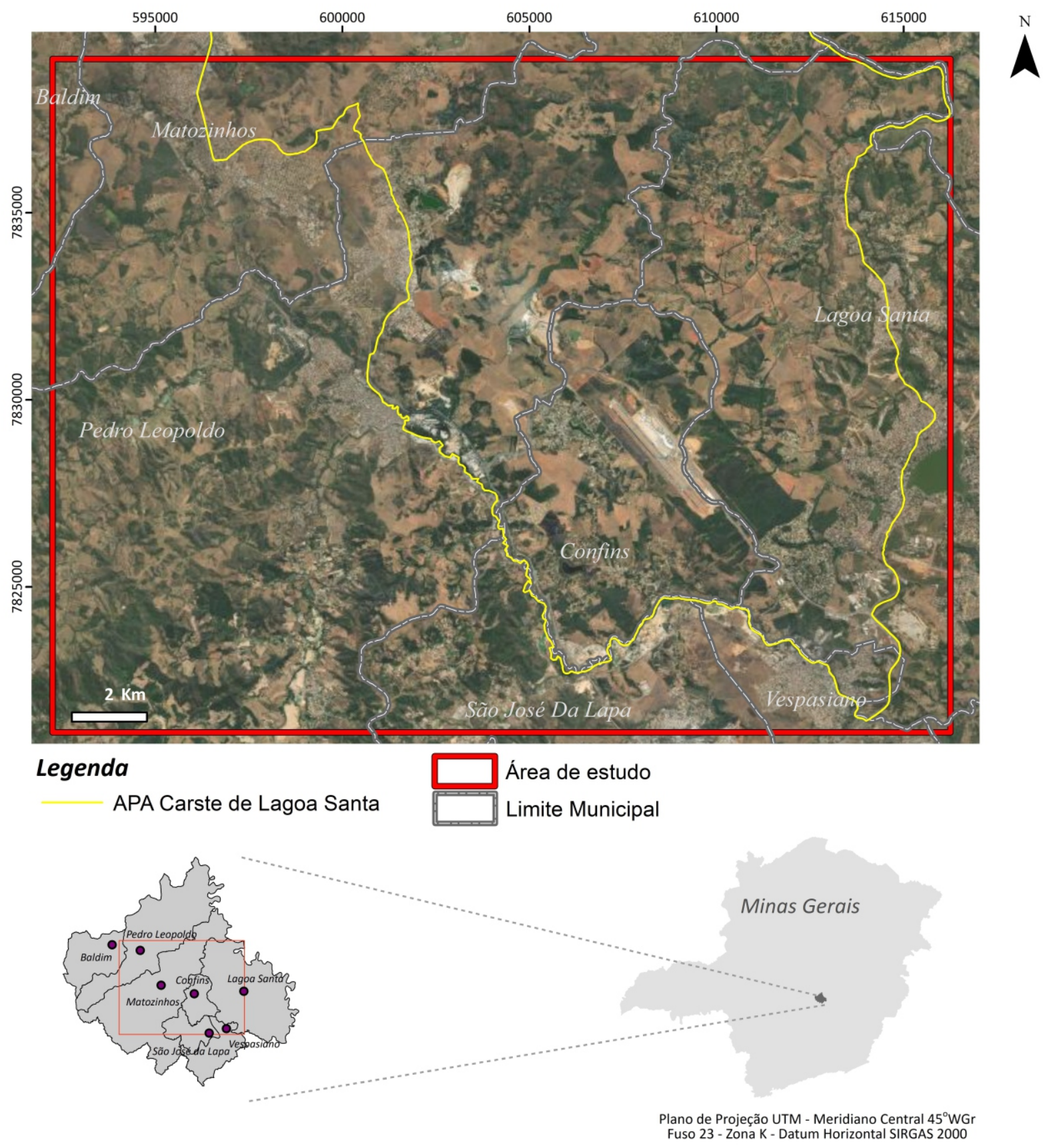

Figura 1 - Localização da área de estudo

O Supergrupo São Francisco possui influência direta da Faixa Araçuaí à leste (ALKMIM et al., 1989), sendo possível distinguir, na área de estudo, três etapas deformacionais de caráter distensivas, compressivas e distensivas, respectivamente (RIBEIRO et al., 2003). A primeira etapa distensiva caracteriza-se por ser de alto ângulo, com falhas mergulhando para leste e trend para NNW-SSE. A segunda fase, compressional e progressiva, originada a partir de um cisalhamento de baxo ângulo, com orientação preferencial para N-S, falhas de empurrão sub-horizontais, zonas de cisalhamento interestratais, dobras e foliações de baixo ângulo de mergulho, nessa etapa, não há envolvimento do embasamento - tectônica thin skinned. A terceira e última fase distensiva envolve movimentos extensionais do embasamento, com deformação da cobertura e geração de sinformes e antiformes de eixo $\mathrm{E}-\mathrm{W}$, além de falhas de rejeito.

Nas rochas do Complexo Basal os resguardos das deformação são de difícil discernimento, sendo manifestadas desenvolvimento de foliação, além do bandamento gnáissico, presença de feixes de diques de rochas básicas com orientação NNW-SSE e veios de quartzo de direção ENE-WSW.

\section{HIDROGEOLOGIA}

Dois tipos de aquíferos são distinguidos na área de estudo, aquíferos porosos-fraturados, associado às rochas do Complexo Granítico, e aquíferos cársticosfissurais associados às rochas do Grupo Bambuí. 
A natureza fissural desses aquíferos possui uma relação intrínseca com a herança geoestrutural e evolução geotectônica local, de modo que as fraturas existentes nas rochas são o principal meio de transmissão de fluídos através da porosidade secundária (Mourão, 2007).

Dessa forma, Da Silva (1994) caracterizou as direções de maior produtividade no município de Belo Horizonte nas rochas do Complexo sendo elas NW, N-S e N35E e, secundariamente, na orientação $\mathrm{E}-\mathrm{W}$. $\mathrm{O}$ aquífero porosofraturado, em termos gerais, apresenta baixa produtividade, com vazões entre 5 a $10 \mathrm{~m}^{3} / \mathrm{h}$, mensuradas nos poços profundos com 80 a $100 \mathrm{~m}$ de profundidade e com a espessura da porção saturada inferior a $70 \mathrm{~m}$. O aquífero do complexo, em geral, apresenta caráter heterogêneo e anisotrópico, com espessura variável e de baixa produtividade.

Para a região cárstica em questão, onde afloram rochas pelito-carbonáticas, os aquíferos são cársticos, semiconfinados a livres. De maneira geral, são formados por um sistema de fraturas, fissuras e cavidades, além de dolinas que se intercomunicam com a subsuperfície e que favorecem a infiltração de água, com elevada produtividade (DE CASTRO et al., 2008).

No estudo proposto por Ribeiro et al., (2003), as zonas de maior produtividade da Formação Sete Lagoas se orientam para N15-25E e N35-45W. Os poços nesse litotipo apresentam vazão entre 7 a $38 \mathrm{~m} / \mathrm{h}$, com média de 33 a $170 \mathrm{~m}$ de profundidade.
A relação das estruturas nas formações Sete Lagoas na área da APA Carste de Lagoa foi feita por Ribeiro et al., (2016). Os dados apresentados em sua pesquisa mostraram que a direção N70-90W e N80-90E são direções preferenciais para a condução de água no sistema cárstico e que a direção N20-60E é secundária.

Com o objetivo de entender a relação hidráulica entre o Complexo Belo Horizonte e as rochas supracrustais decidiu-se incorporar os dados estruturais levantados por Ribeiro et al., (2016) ao presente estudo.

\section{MÉTODOS}

O mapeamento da anisotropia na área de estudo consistiu na análise e interpretação de imagens de satélites (ALOS PALSAR resolução de 12,5 x 12,5 m, 2016), fotointerpretação de lineamentos (modificado de VELÁSQUEZ et al., 2016) e na medição de estruturas rúpteis em campo.

Realizou-se, então, um tratamento estatístico dos dados, com a elaboração de rosetas dos lineamentos fotointerpretados em comparação com os estereogramas das estruturas rúpteis mensuradas em campo. Inicialmente, essa associação foi feita dentro da própria unidade e posteriormente entre ambos grupos rochosos. Nessa etapa redirecionou-se a análise estatística para as rochas do Complexo Belo Horizonte e da Formação Sete Lagoas, devido ao comportamento semelhante frente às tensões.
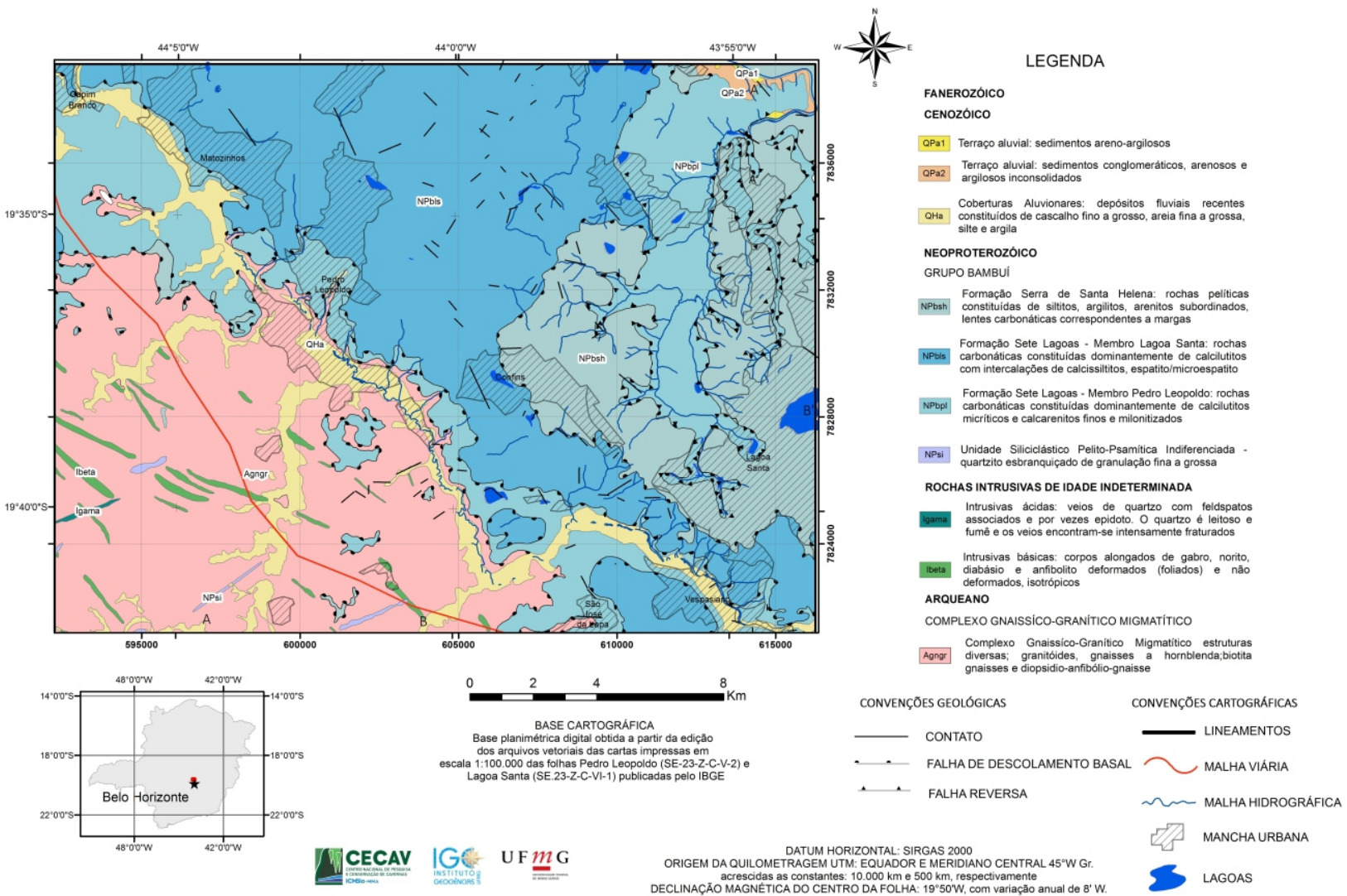

"本.

LEGENDA

FANEROZÓICO

CENOZOOICO

OPa1 Terraço aluvial: sedimentos areno-argilosos

Terraço aluvial: sedimentos conglomeráticos, arenosos e
OP.22

Coberturas Aluvionares: depósitos fluviais recentes
Oonstituidos de cascalho fino a grosso, areia fina a grossa,
silte e argila

NEOPROTEROZÓICO

GRUPO BAMBUI

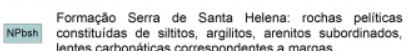

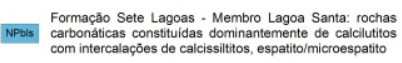

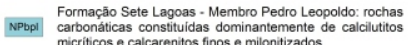

NPsil Unidade Siliciclastico Pelito-Psamitica Indifierenciada

ROCHAS INTRUSIVAS DE IDADE INDETERMINADA

Intrusivas ácidas: veios de quartzo com feldspatos
associados e por vezes epidoto. 0 quartzo e le leitoso 0

Intrusivas básicas: corpos alongados de gabro, norito,
diabásio e anfibolito deformados (foliados)

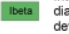

ARQUEANO

COMPLEXO GNAISSICO-GRANITICO MIGMATITICO

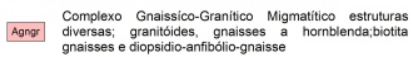

Figura 2 - Contexto geológico da porção sul da APA Carste de Lagoa Santa modificado de Ribeiro et al., (2003). 
Os dados hidráulicos dos aquíferos foram obtidos a partir de informações dos poços tubulares outorgados. As fontes dos bancos de dados são oriundas do Sistema de Informações de Águas Subterrâneas - SIAGAS, pertencente do Serviço Geológico do Brasil, a Companhia de Saneamento Básico de Minas Gerais - COPASA MG, poços outorgados pelo Instituto Mineiro de Gestão das Águas - IGAM, disponibilizados na Superintendência Regional de Meio Ambiente - SUPRAM Metropolitana e de poços novos encontrados em campo. Dessa forma, validou-se em campo 123 poços que constavam no banco de dados, e incorporação de novos 67 poços.

A partir dos dados locacionais dos poços tubulares e do cálculo da capacidade específica dos poços em cada litologia (Complexo Granítico e Formação Sete Lagoas), com complementos obtidos pela classificação hidroquímica das unidades aquíferas propostas por Vieira (2018) dos poços profundos, foi possível associar a produtividade dos aquíferos com as direções azimutais dos lineamentos traçados. Obtida a produtividade e, a partir de uma relação com os azimutes dos fotolineamentos, identificou-se as direções favoráveis para a interconexão hidráulica entre os aquíferos porosofraturado (Complexo Belo Horizonte) e aquíferos cársticos-fissurais (Formação Sete Lagoas).

Estabeleceu-se, então, as áreas de maior potencial aquífero a partir da produtividade, isto é, da capacidade específica dos poços em relação aos azimutes dos lineamentos estruturais tanto no Complexo Belo Horizonte quanto à Formação Sete Lagoas.

Para a espacialização da produtividade elaborou-se um mapa de isolinhas da capacidade específica utilizando o método de interpolação IDW (Ponderação do Inverso da Distância) pelo software ArcGis, o qual assume que cada ponto tem uma influência local que diminui com o aumento da distância.

\section{RESULTADOS}

A análise dos dados partiu da conferência das direções principais dos lineamentos fotointerpretados das unidades litoestratigráficas com as medidas obtidas em campo (Figura 3).

Os estereogramas foram gerados (Figura 4), e observouse que as direções principais de lineamentos no Complexo Granítico-Gnáissico Migmatítico foram N4050E e N40-60W, e que essas, repercutem nas fraturas dessa unidade, segundo a mesma ordem. Na Formação Sete Lagoas os lineamentos principais dessa unidade em ordem decrescente de frequência foram, N40-60E, N50$60 \mathrm{~W}, \mathrm{E}-\mathrm{W}, \mathrm{N} 30-40 \mathrm{E}$, e N0-10W, que também refletem nas fraturas, porém em ordem de frequência decrescente praticamente inversa: E-W, N0-10W, N30-40E e N50-60E. Isso indica que na unidade carbonática, os fraturamentos mais frequentemente medidos em campo, não são, necessariamente, os que mais são expressos no relevo sob a forma de lineamentos. Porém, tais fraturas, como se verá a seguir, funcionam como zonas aquíferas cárstico-fissurais.
Comparando-se os lineamentos entre ambas as unidades, verifica-se um padrão do arranjo dessas estruturas, inclusive na ordem das frequências (e Figura 4), concordantes em NE e NW. Quanto aos fraturamentos, essa similaridade entre as unidades é mais fraca, com as máximas direções da Fm. Sete Lagoas (E-W e NO-10W) praticamente insignificantes no Complexo Gnáissico.

Comparando-se as fraturas das unidades, observa-se que no quadrante NE e NW as fraturas N30-40E, N50-60E e N50-60W são concordantes no Complexo Granítico e na Formação Sete Lagoas. Essas direções similares nas unidades podem caracterizar melhores condições geométricas e podem ser os prováveis meios condutores de fluxos de água subterrânea do Complexo adentrando para os aquíferos da Fm. Sete Lagoas. Dentro dessa formação a circulação profunda da água se dá através de dutos e fraturas alargadas pela dissolução do calcário, cujas direções mais importantes serão tratadas posteriormente.

Tabela 1 : Direção preferencial e secundária dos lineamentos e fraturas do Complexo Granitico-Gnáissico e da Formação Sete Lagoas

\begin{tabular}{|c|c|c|}
\hline DIREÇÕES X LITOTIPO & $\begin{array}{l}\text { COMPLEXO GRANÍTICO-GNÁISSICO } \\
\text { MIGMATÍTICO }\end{array}$ & $\begin{array}{l}\text { FORMAÇÃO SETE } \\
\text { LAGOAS }\end{array}$ \\
\hline LINEAMENTOS 1a ORDEM & N50-60E & N40-50E \\
\hline LINEAMENTOS 2a ORDEM & N50-60W & N50-60E \\
\hline LINEAMENTOS 2a ORDEM & N40-50W & N40-50W \\
\hline LINEAMENTOS 2a ORDEM & N40-50E & N80-90W \\
\hline FRATURAS 1a ORDEM & N50-60E & N80-90E \\
\hline FRATURAS 1 ORDEM & N50-60W & NO-10W \\
\hline FRATURAS 1a ORDEM & N40-50W & N80-90W \\
\hline FRATURAS 2 a ORDEM & N20-30E & N50-60W \\
\hline FRATURAS 2a ORDEM & N30-40E & N60-70W \\
\hline FRATURAS 2a ORDEM & N40-50E & N50-60E \\
\hline FRATURAS 2a ORDEM & N70-80E & N30-40E \\
\hline
\end{tabular}

De modo a se averiguar a relação entre a produtividade dos poços com os lineamentos fotointerpretados realizou-se o cálculo da capacidade específica para 96 poços tubulares que continham informações acerca do nível estático, nível dinâmico e vazão.

Verificou-se que dos 96 poços, cerca de 75 estão associados aos lineamentos (Figura 5) e estes apresentaram uma mediana de produtividade 10 vezes superior $\left(3,21 \mathrm{~m}^{3} / \mathrm{h} / \mathrm{m}\right)$ aos 21 poços que não associados aos lineamentos $\left(0,31 \mathrm{~m}^{3} / \mathrm{h} / \mathrm{m}\right)$ - Tabela 2 e Tabela 3 .

Seguiu-se a investigação da produtividade dos poços tubulares em relação às direções preferenciais dos lineamentos fotointerpretados, para cada grande unidade litológica - Complexo Granítico-Gnáissico e da Formação Sete Lagoas (Tabela 4 e Tabela 5).

Tabela 2 : Cálculo da capacidade específicos dos poços associados com lineamentos

\begin{tabular}{lc}
\hline POÇOS ASSOCIADOS COM LINEAMENTOS $=75$ & \\
\hline PARÂMETROS & CAPACIDADE ESPECÍFICA $\left(\mathrm{m}^{3} / \mathrm{h} / \mathrm{m}\right)$ \\
\hline MÉDIA & 18,44 \\
\hline MEDIANA & 3,21 \\
\hline MÍNIMO & 0,01 \\
\hline MÁXIMO & 305,08 \\
\hline
\end{tabular}




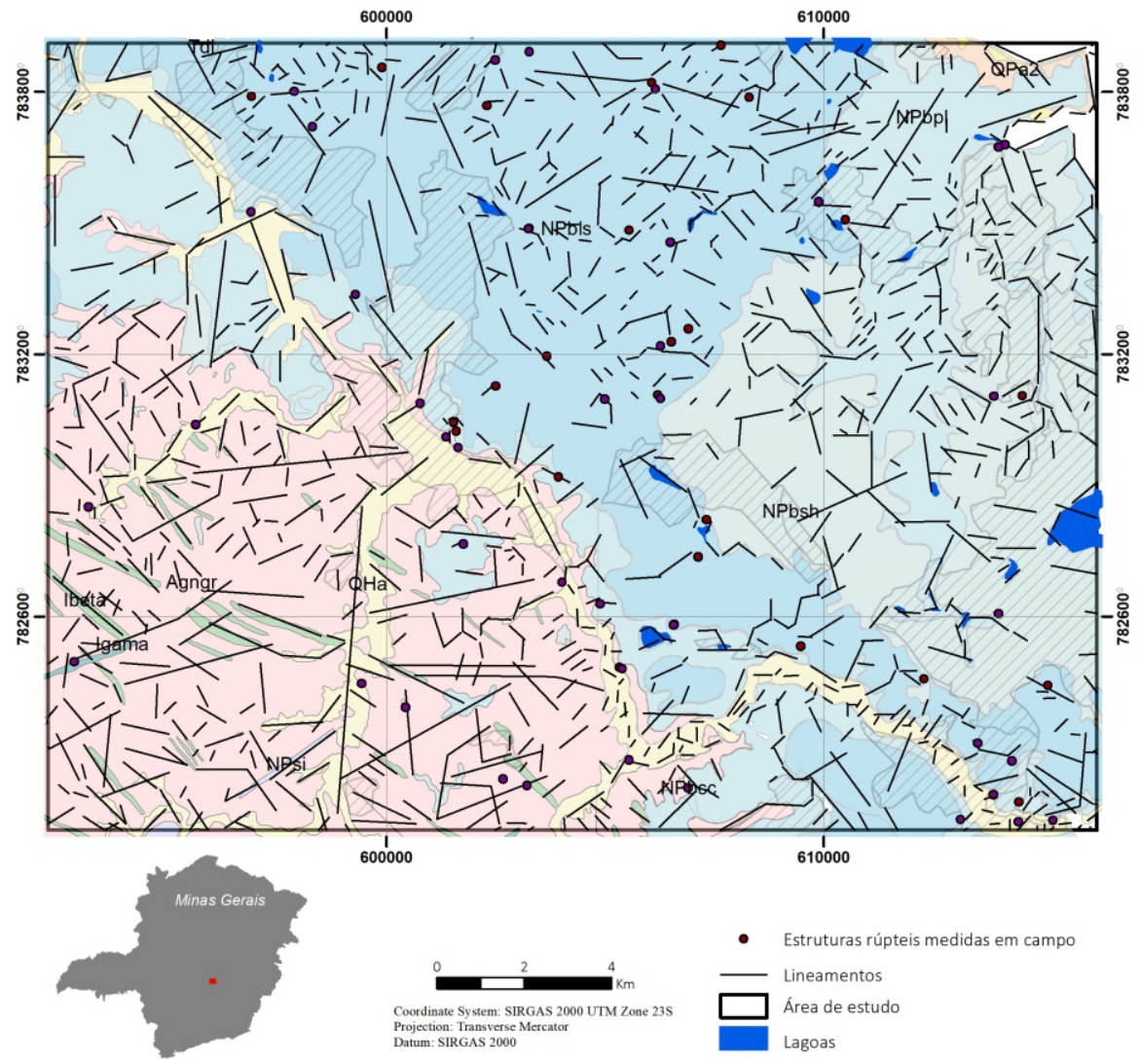

Legenda

CENOZÓICO
Tdl Terraço aluvial: sedimentos areno-argilosos
$\mathrm{QPa2}$ Terraço aluvial: sedimentos conglomeráticos, arenosos e argilosos inconsolidados
Coberturas Aluvionares: depósitos fluviais recentes constituidos de cascalho fino a grosso, areia fina a grossa, silte e argil
NEOPROTEROZÓICO GRUPO BAMBUÍ
Formação Serra de Santa Helena: rochas peliticas
NPbsh constituidas de siltitos, argilitos, arenitos subordinados, lentes carbonáticas correspondentes a margas. formação Sete Lagas - Membro Lagoa Santa: rochas carbonáticas constituidas dominantemente de
calcilutitos com intercalaçōes de calcissiltitos, espatito/microespatito e brechas Formação Sete Lagoas - Membro Pedro Leopoldo:
NPbpl rochas carbonáticas constituidas dominantemente de calcilutitos micríticos e calcarenitos finos $\mathrm{e}$ milonitizados protoderivados. Unidade Siliciclástico Pelito-Psamítica Indiferenciada -
NPbsc siltito e paraconglomerado polimítico de matriz arcoseana fina e grossa com predomínio de seixos e grânulos
ARQUEANO
COMPLEXO GNAISSICO-GRANITICO MIGMATÍTICO
Complexo Gnaissico-Granitico Migmatítico estruturas diversas; granitóides, gnaisses a hornblenda;biotita enaisses e diopsidio-anfibólio-gnaisse
ROCHAS INTRUSIVAS DE IDADE INDETERMINADA
Intrusivas ácidas: veios de quartzo com feldspatos associados e por vezes epidoto. 0 quartzo é leitoso e fumê ê os vejo encontram-se intensamente fratura Intrusivas basicas: corpos alongados de gabro, nonito, diabasio e antibolto deformados (foliados) e na.

Figura 3-Lineamentos fotointerpretados (modificado de Velásquez et al., 2016) associados com medidas estruturais realizadas em campo.

Lineamentos Complexo Granítico-Gnaíssico

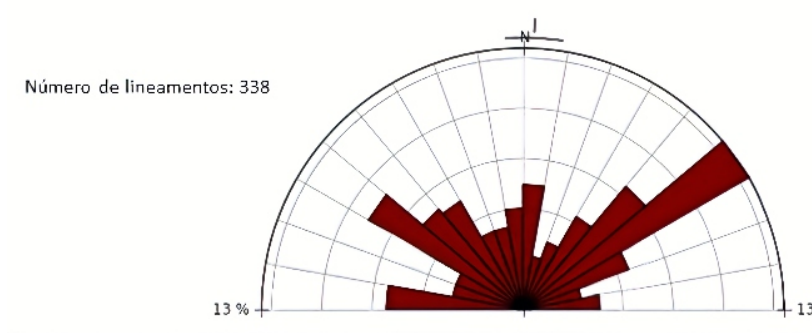

Fraturas Complexo Granítico-Gnaíssico

Número de fraturas: 35

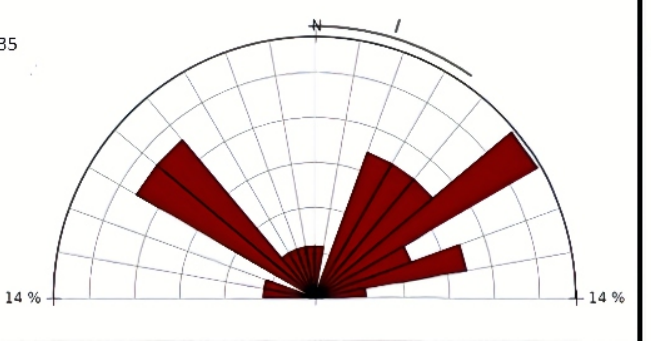

Lineamentos Formação Sete Lagoas

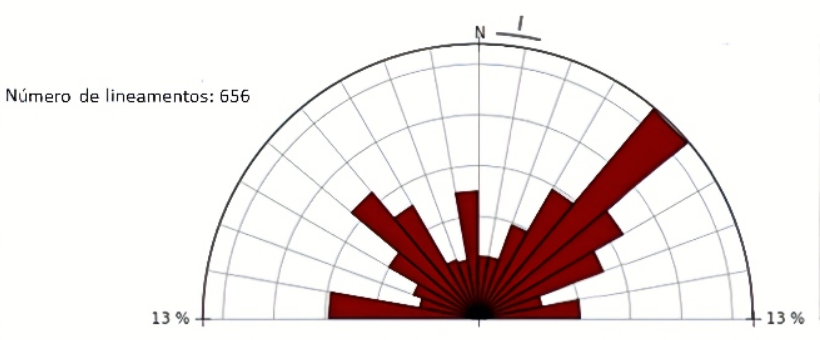

Fraturas Formação Sete Lagoas

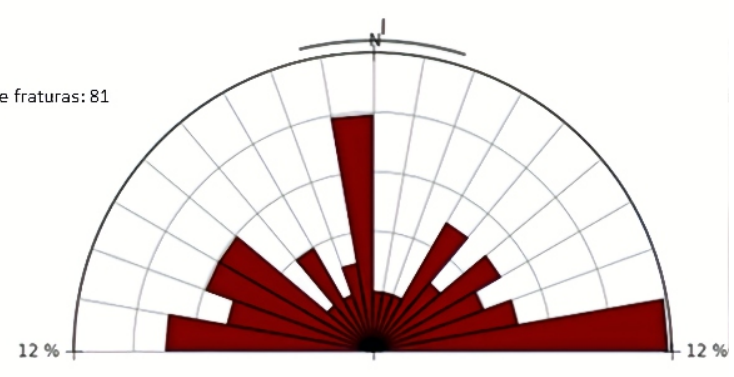

Figura 4-Rosetas dos lineamentos e das fraturas do Complexo Granítico-Gnáissico e da Formação Sete Lagoas pertencente ao Grupo Bambuí 
As zonas aquíferas do Complexo apresentaram os maiores valores de capacidade específica na direção N30$60 \mathrm{E}\left(2,07 \mathrm{~m}^{3} / \mathrm{h} / \mathrm{m}\right)$, enquanto a direção de maior produtividade na Formação Sete Lagoas foi a direção E-W (N60-90E e N60-90W), com capacidade específica mediana de $5,52 \mathrm{~m}^{3} / \mathrm{h} / \mathrm{m}$. Ainda digno de nota é a superioridade da produtividade das zonas aquíferas da Fm. Sete Lagoas em relação às do embasamento, conforme esperado, devido a sua natureza cárstica.

De acordo com Ribeiro et al., (2016) os poços de elevada produtividade estão associados à direção preferencial EW, principal dentre as estruturas rúpteis na área de estudo. Ressalta-se, assim, a importância da direção N30$60 \mathrm{E}$ no embasamento que pode atuar como condutora de fluxos nos sentidos N-S (NO-30

A Figura 6 representa a capacidade específica dos poços de todas as unidades aquíferas. Nota-se os menores valores numa faixa de direção SW-NE desde o embasamento adentrando-se para os terrenos calcários do Grupo Bambuí onde tendem a aumentarem gradativamente. Os maiores valores, acima de 2,5 $\mathrm{m}^{3} / \mathrm{h} / \mathrm{m}$, estão nos terrenos supracrustrais, encontrados nos extremos NW e SE da área, atingindo os maiores valores neste último. W a N0-30E) e/ou E-W (N60-90E e N60-90W).

A Figura 6 representa a capacidade específica dos poços de todas as unidades aquíferas. Nota-se os menores valores numa faixa de direção SW-NE desde o embasamento adentrando-se para os terrenos calcários do Grupo Bambuí onde tendem a aumentarem gradativamente. Os maiores valores, acima de 2,5 $\mathrm{m}^{3} / \mathrm{h} / \mathrm{m}$, estão nos terrenos supracrustrais, encontrados nos extremos NW e SE da área, atingindo os maiores valores neste último.

Tabela 3: Cálculo da capacidade específicos dos poços não associados com lineamentos

\begin{tabular}{lc}
\hline POÇOS NÃO ASSOCIADOS COM LINEAMENTOS $=21$ & \\
\hline PARÂMETROS & CAPACIDADE ESPECíFICA $\left(\mathrm{m}^{3} / \mathrm{h} / \mathrm{m}\right)$ \\
\hline MÉDIA & 3,51 \\
\hline MEDIANA & 0,31 \\
\hline MÍNIMO & 0,01 \\
\hline MÁXIMO & 44,47 \\
\hline
\end{tabular}

Tabela 4: Associação dos poços com as direções de lineamentos no Complexo Granítico-Gnáissico Migmatítico

\begin{tabular}{cccc}
\hline \multirow{2}{*}{ COMPLEXO GRANíTICO-GNÁISSICO MIGMATítICO } & \multirow{2}{*}{ POÇOS SEM LINEAMENTOS = 6 } \\
\cline { 2 - 4 } PARÂMETROS & \multicolumn{3}{c|}{ CAPACIDADE ESPECÍFICA } \\
\cline { 2 - 4 } & MÉDIA & MEDIANA & № DE POÇOS \\
\hline N0-30W a N0-30E & 0,25 & 0,17 & 4 \\
\hline N30-60E & 4,04 & 2,07 & 3 \\
\hline N30-60W & 0,79 & 0,21 & 3 \\
\hline
\end{tabular}

Tabela 5: Associação dos poços com as direções de lineamentos da Formação Sete Lagoas

\begin{tabular}{|c|c|c|c|c|}
\hline \multicolumn{4}{|c|}{ FORMAÇÃO SETE LAGOAS } & POÇOS SEM LINEAMENTOS $=15$ \\
\hline \multirow[t]{2}{*}{ PARÂMETROS } & \multicolumn{3}{|c|}{ CAPACIDADE ESPECIFICA } & \\
\hline & MÉDIA & MEDIANA & № DE POÇOS & \\
\hline NO-30W a N0-30E & 15,71 & 4,30 & 14 & \\
\hline N30-60E & 25,94 & 1,37 & 18 & \\
\hline N30-60W & 15,11 & 3,20 & 14 & \\
\hline N60-90E e N60-90W & 11,37 & 5,52 & 18 & \\
\hline
\end{tabular}

\section{CONCLUSÕES}

As fraturas no Complexo Belo Horizonte possuem direções principais para NW e NE, enquanto nas rochas da Formação Sete Lagoas as direções preferenciais são NS e EW. Em relação aos lineamentos, as rochas do embasamento compreendem direção preferencial NE e foi observado o mesmo padrão para os lineamentos fotointerpretados do Grupo Bambuí.

Através da análise acerca da anisotropia das rochas do Complexo Belo Horizonte com o Grupo Bambuí foi possível reconhecer feições rúpteis com direções equivalentes e correspondentes em ambos os litotipos. Essas direções foram consideradas essenciais para a análise do fluxo hídrico entre as rochas do Complexo Basal e as rochas supracrustais.

Os dados hidráulicos provenientes dos poços tubulares foram, então, associados com as estruturas rúpteis, de modo a se determinar as porções mais produtivas da área de estudo a partir dos valores de capacidade específica calculados. Desse modo, concluiu-se que a direção de fraturas NE do embasamento pode ser a via de contribuição no fluxo subterrâneo para as unidades aquíferas do Grupo Bambuí, a partir de onde seguem preferencialmente na direção $\mathrm{E}-\mathrm{W}$, mais produtiva, em contraste com a direção $\mathrm{NE}$, menos produtiva nessa área. A baixa capacidade específica dos poços no Bambuí nesta direção NE desde o embasamento, e o seu gradual aumento no sentido NW-SE, corrobora para a hipótese da baixa transferência de água subterrânea oriunda do embasamento.

Dessa forma, pode-se partir da hipótese que a transferência de água do embasamento cristalino através das fraturas NE para os aquíferos do Grupo Bambuí ocorre e que posteriormente o fluxo d'água segue preferencialmente para as fraturas que direcionam-se para E-W (N60-90E e N60-90W) (Tabela 5). Porém a Figura 6 mostra que, admitindo essa hipótese, esses fluxos são fracos, como mostrado na faixa central de baixa produtividade adentrando para a região supracrustral a partir dos terrenos do embasamento, em contraste com as faixas produtivas a NW e SE desta faixa, que possuem continuidade lateral com calcários fora dos limites da área estudada.

\section{REFERÊNCIAS BIBLIOGRÁFICAS}

ALOS PALSAR (2018). Disponível em: < https://www.asf.alaska.edu/sar-data/palsar/>. Acesso em: abr 2018.

COSTA M.T.; BRANCO J.J.R. Introdução. In: Branco J.J.R. (ed.) Roteiro para a excursão Belo Horizonte-Brasília. In: SBG, Congr. Bras. Geol., 14, Belo Horizonte, Anais, 15:1-119, 1961.

COMPANHIA DE RECURSOS E SERVIÇOS MINERAIS (CPRM) 2018. Hidrogeologia: conceitos e aplicações. 3ed.p. 835.

DA SILVA, ADELBANI BRAZ. Estudo Hidrogeologico do municipio de Belo Horizonte-MG. Águas Subterrâneas, 1994. 

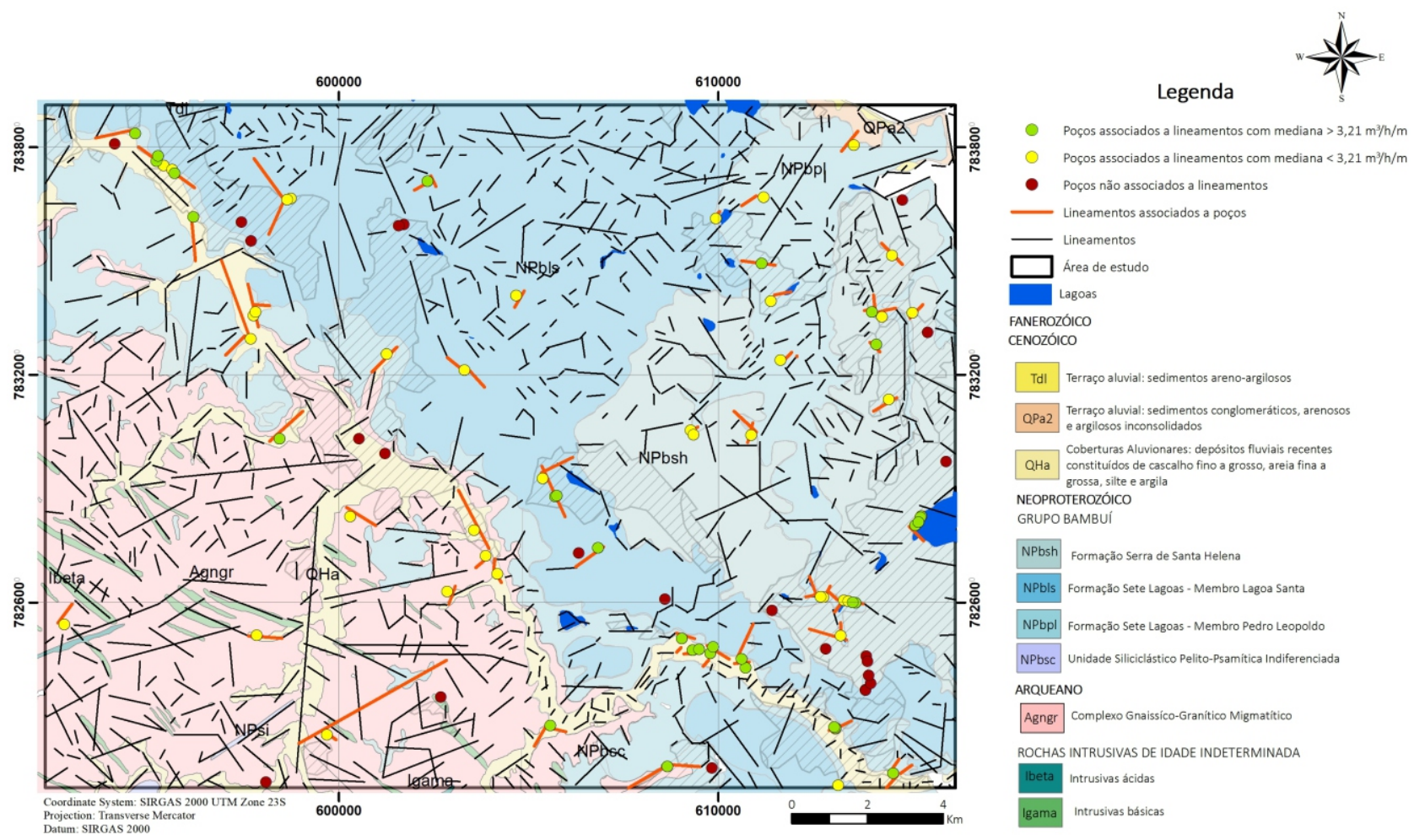

Figura 5-Distribuição dos poços associados aos lineamentos

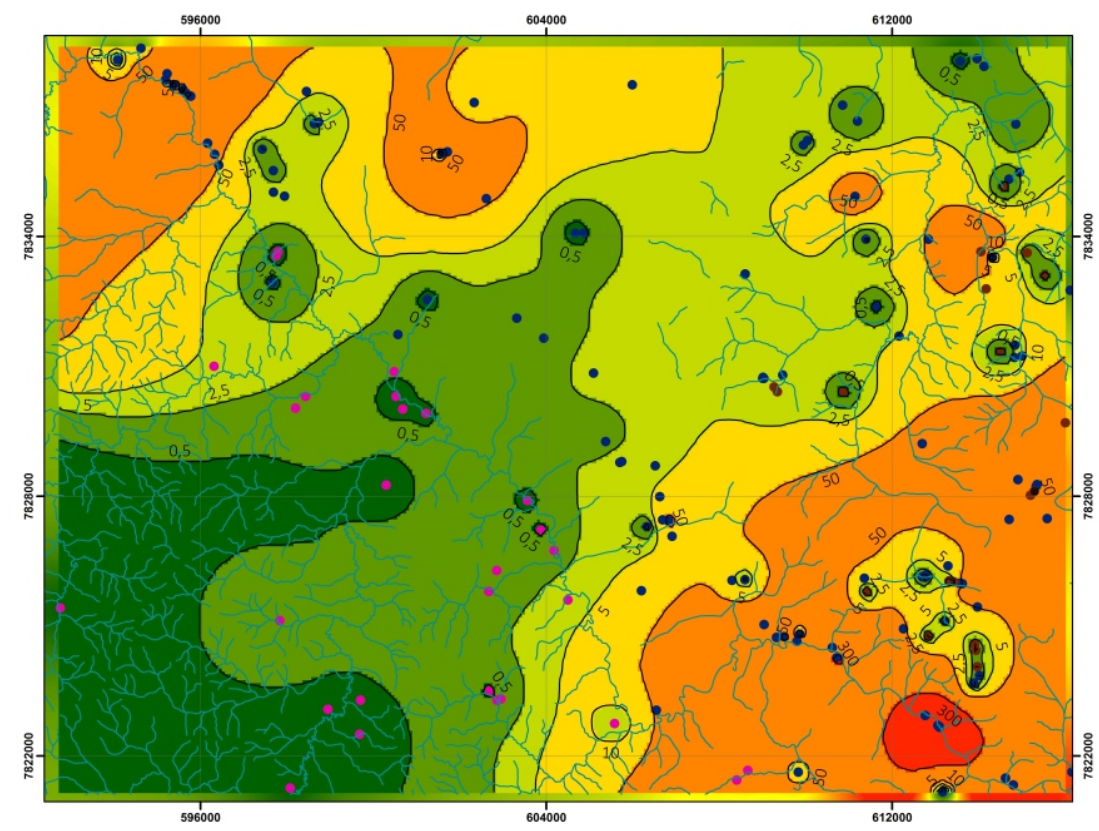

LEGENDA

CAPACIDADE ESPECÍFICA $\left(\mathrm{m}^{3} / \mathrm{h} / \mathrm{m}\right)$

HIDROGRAFIA

ÁREA TG

UNIDADES AQUÍFERAS DOS POÇOS TUBULARES

- FORMAÇÃo SERRA DE SANTA HELENA

- formação sete lagoas

- complexo granítico-gnaíssico migmatítico CAPACIDADE ESPECÍFICA $\left(\mathrm{m}^{3} / \mathrm{h} / \mathrm{m}\right)$
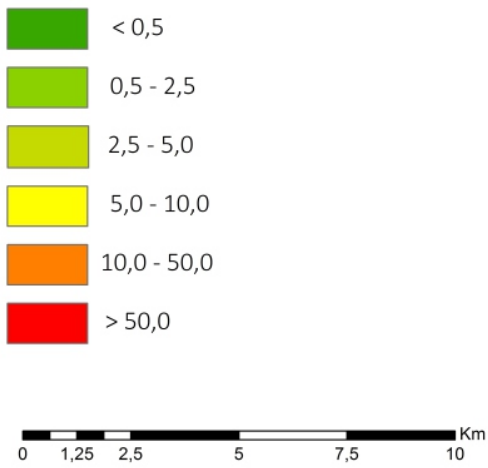

Figura 6-Mapa de isolinhas da capacidade específica $\left(\mathrm{m}^{3} / \mathrm{h} / \mathrm{m}\right)$ dos poços na área de estudo

DE CASTRO, E.; LOUREIRO D.O.C; VIANA, J.H.M. Estudo hidrogeológico ambiental em região cárstica no município de sete lagoas-minas gerais: comportamento de nitratos e da atrazina. Águas Subterrâneas, 2008.

MARTINEZ, M.I. 2007. Estratigrafia e Tectônica do Grupo Bambuí no Norte do Estado de Minas Gerais. Universidade Federal de Minas Gerais, Tese de Mestrado.p. 144
Mourão M.A.A. 2007. Caracterização hidrogeológica do Aquífero Cauê: Subsídios para a gestão de recursos hídricos no Quadrilátero Ferrífero. Tese (Doutorado), Universidade Federal de Minas Gerais. Belo Horizonte. 297p.

RIBEIRO, J.H. et al. Projeto VIDA: mapeamento geológico, região de Sete Lagoas, Pedro Leopoldo, Matozinhos, Lagoa Santa, Vespasiano, Capim Branco, Prudente de 
Morais, Confins e Funilândia, Minas Gerais - relatório final, escala 50.000. 2. ed. Belo Horizonte: CPRM, 2003.

RIBEIRO, C. G. et al. Levantamento Geológico Estrutural Aplicado aos Fluxos dos Aquíferos Cárstico-Fissurais da Regiões da APA Carste de Lagoa Santa, Minas Gerais. Trabalho Geológico de Graduação em Geologia. Instituto de Geociências, Universidade Federal de Minas Gerais, 2016.

VELÁSQUEZ et al., Relatório Técnico. Projeto de Adequação e Implantação de uma Rede de Monitoramento de Águas Subterrâneas na área piloto da APA Carste de Lagoa Santa, MG. Universidade Federal de Minas Gerais, 2016.

VIEIRA, Luisa Costa Martins. Hidrogeoquímica dos Aquíferos da Região da APA Carste de Lagoa Santa, MG, 2018. 